\title{
Asymmetric Synthesis of a Carbapenem Intermediate
}<smiles>COC(=O)C(CNC(=O)Oc1ccccc1)C(C)=O</smiles>

A<smiles>CC(O)C1CNC(=O)C1(C)O</smiles>

$\mathbf{F}$
$\mathrm{mp}=66^{\circ} \mathrm{C}$

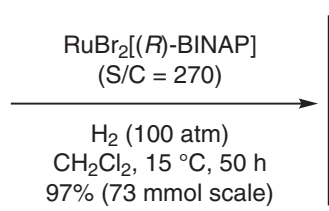

$97 \%(73 \mathrm{mmol}$ scale)

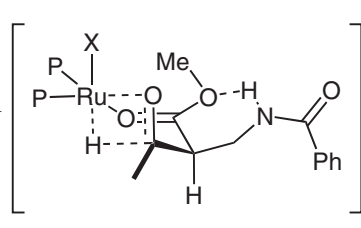

B

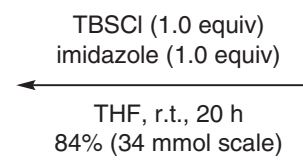

$84 \%$ (34 mmol scale)

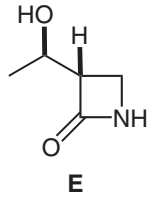

E

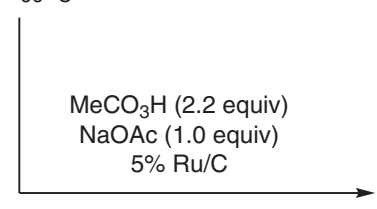

$\mathrm{AcOH}$, r.t., $2.5 \mathrm{~h}$ $99 \%$ (4.4 mmol scale) J. Am. Chem. Soc. 1990, 112, 7820

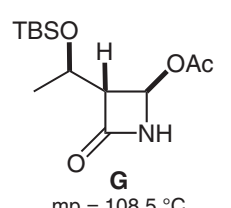

$\mathrm{mp}=108.5^{\circ} \mathrm{C}$

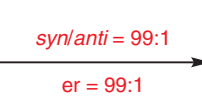<smiles>COC(=O)C(CNC(=O)Oc1ccccc1)C(C)O</smiles>

C

1. $10 \% \mathrm{HCl}, 4.5 \mathrm{~h}$

2. $\mathrm{Et}_{3} \mathrm{~N}, \mathrm{MeCN}$

$79 \%$ (42 mmol scale)

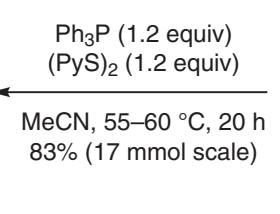<smiles>CC(O)C(CN)C(=O)O</smiles>

mp not reported

Products and

Potential Drugs

Key words

carbapenems

asymmetric hydrogenation

dynamic kinetic resolution

$\beta$-lactams

ruthenium catalysis

Significance: Azetidinone $\mathbf{G}$ is a key intermediate in the commercial synthesis of carbapenem antibiotics such as Meropenem. Many syntheses of $\mathbf{G}$ have been reported (see first Review below). One of the simplest and shortest was developed jointly by workers at Takasago and the Noyori group, that is conspicuous for being an early example of the practical application of asymmetric catalytic hydrogenation and dynamic kinetic resolution in the construction of APIs.

Reviews: A. H. Berks Tetrahedron 1996, 52, 331375; H. Kumobayashi, T. Miura, N. Sayo, T. Saito, X. Zhang Synlett 2001, 1055-1064.
Comment: Over 100 tons of $\mathbf{G}$ are produced annually by Takasago using a variation of the process depicted. The conditions and yields for $\mathbf{C} \rightarrow \mathbf{F}$ are taken from a patent by Takasago International Corporation (N. Sayo, T. Saito, Y. Okeda,

H. Nagashima, H. Kumobayashi, US Pat. 4,981,992; January 1, 1991). There have been many improvements and refinements in the asymmetric hydrogenation that have increased the turnover number, reduced the catalyst load, and improved the de and ee of the process (see second Review below). For a multikilogram-scale synthesis of the starting $\beta$-keto ester A, see: M. Chao, A. Hao, H. Wang Org. Process Res. Dev. 2009, 13, 645. 